\title{
UMA VISÃO SOBRE EDUCAÇÃO AMBIENTAL CRÍTICA A PARTIR DO PROJETO EDUCACIONAL "NOVA MENTE"
}

\author{
Aparecida dias de Macedo ${ }^{1}$ \\ Ariane Delprete Faria²
}

\section{RESUMO}

Este artigo discorre sobre a importância de uma abordagem efetiva da Educação Ambiental Crítica no espaço escolar formal e não formal. Seu objetivo é analisar a experiência educativa dos alunos do ensino fundamental II da EMEF "Sebastião Costa" mediante a participação no projeto "Nova Mente'. Realizou-se uma pesquisa qualitativa envolvendo 68 alunos da EMEF "Sebastião Costa". Em concordância com os autores Layrargues (2002), Layrargues e Lima (2011), Dias (1991) e Sato (2010) a Educação Ambiental na escola deve levar ao desenvolvimento crítico do aluno onde ele seja capaz de refletir e agir no meio em que vive, ou seja, dentro e fora da escola, exercendo sua cidadania. Percebe-se que na escola os alunos participam efetivamente do projeto, mas quando estão em suas residências há resistência em realizar a separação. A maioria não considera difícil executar o projeto, reconhece as melhorias trazidas por ele, tanto na escola como na comunidade e principalmente, que precisam melhorar suas posturas enquanto participantes efetivos da separação e coleta seletiva dos resíduos sólidos, significando que o projeto está no caminho certo, mas que ainda há muito que desenvolver na vida de seus protagonistas em busca de uma verdadeira Educação Ambiental Crítica. Os resultados desta pesquisa indicam que a escola, enquanto educadora e transformadora da sociedade, pode contribuir na mudança de hábitos com relação ao meio ambiente.

Palavras Chaves: Educação Ambiental Crítica. Escola. Experiência educativa.

\section{ABSTRACT}

This article discusses the importance of an effective approach to critical environmental education in the formal and non formal school space. Its objective is to analyze the educational experience of elementary school students II of EMEF "Sebastião Costa" through participation in the Nova Mente project. A qualitative research was carried out involving 68 students from EMEF "Sebastião Costa". In agreement with the authors

\footnotetext{
${ }^{1}$ Graduada em Licenciatura Plena em Matemática pela Faculdade de Filosofia, Ciências e Letras de Alegre, graduada em Licenciatura Plena em Geografia pela Universidade Metropolitana de Santos, especialista Lato sensu em Matemática pela Faculdades Integradas de Jacarepaguá, , aluna do curso de Mestrado pela Facultad Interamericana de Cièncias Sociales- FICS, atua como professora na rede municipal de Muniz Freire.

2 Graduada em Licenciatura Plena em Ciências Biológicas pela Faculdade de Filosofia, Ciências e Letras de Alegre, especialista Lato sensu em Educação Ambiental e Recursos Naturais pela Faculdade de Ciências e Letras de Alegre, especialista em Ciências Biológicas pela Faculdade do Noroeste de Minas (FINOM), aluna do curso de Mestrado Scricto Sensu pelo Institute of Tecnology Education e Health, atua como professora na rede municipal de Muniz Freire.
} 
Layrargues (2002), Layrargues and Lima (2011), Dias (1991) and Sato (2010) environmental education in the school should lead to the critical development of the student where he is able to reflect and act in the environment in which lives, that is, in and out of school, exercising their citizenship. It is noticed that in the school the students participate effectively of the project, but when they are in their residences there is resistance in accomplishing the separation. Most people do not consider it difficult to carry out the project, recognize the improvements they bring, both at school and in the community, and especially, they need to improve their postures as effective participants in the separation and selective collection of solid waste, meaning that the project is on the right path , but that there is still much to develop in the lives of its protagonists in search of a true Critical Environmental Education. The result of this research affirmed that the school, as educator and transformer of the society, that works with projects of environmental education can contribute in the change of habits with respect to the environment and in the behavior of a population developing in fact a critical environmental education in the formal spaces and non-formal, even at a slow pace.

Keywords: Critical environmental education. School experience.

\section{RESUMEN}

Este artículo discurre sobre la importancia de un enfoque efectivo de la educación ambiental crítica en el espacio escolar formal y no formal. Su objetivo es analizar la experiencia educativa de los alumnos de la enseñanza fundamental II de la EMEF "Sebastião Costa" mediante la participación en el proyecto Nova Mente. Se realizó una encuesta cualitativa que involucró a 68 alumnos de la EMEF "Sebastião Costa". En concordancia con los autores Layrargues (2002), Layrargues y Lima (2011), Dias (1991) y Sato (2010) la educación ambiental en la escuela debe llevar al desarrollo crítico del alumno donde él sea capaz de reflexionar y actuar en el medio en que vive, es decir, dentro y fuera de la escuela, ejerciendo su ciudadanía. Se percibe que en la escuela los alumnos participan efectivamente del proyecto, pero cuando están en sus residencias hay resistencia en realizar la separación. La mayoría no considera difícil ejecutar el proyecto, reconoce las mejoras traídas por él, tanto en la escuela como en la comunidad y principalmente, que necesitan mejorar sus posturas como participantes efectivos de la separación y recolección selectiva de los residuos sólidos, significando que el proyecto está en el camino correcto pero que todavía hay mucho que desarrollar en la vida de sus protagonistas en busca de una verdadera Educación Ambiental Crítica. El resultado de esta investigación afirmó que la escuela, como educadora y transformadora de la sociedad, que trabaja con proyectos de educación ambiental puede contribuir en el cambio de hábitos con relación al medio ambiente y en el comportamiento de una población desarrollando de hecho una educación ambiental crítica en los espacios formales y no formales, incluso a pasos lentos.

Palabras claves: Educación Ambiental Crítica. La escuela. Experiencia educativa. 


\section{INTRODUÇÃO}

Para que a escola seja um lugar de sensibilização das questões ambientais preparando os alunos para desenvolver ações fora dela é preciso que todo o corpo escolar não trabalhe a Educação Ambiental somente em dias marcados no calendário, mas se comprometa a viver a Educação Ambiental todos os dias, formando cidadãos autênticos, críticos e preocupados com as questões sócio ambientais. "E para além de nossas reflexões escolares, um currículo da vida, a mudança de valores que consiga nos tornar pessoas melhores, capazes de enxergar as injustiças do mundo e lutar para que o planeta seja de todos e todas!" (SATO, 2010, p. 77)

Diante dessa utopia o problema que norteou este trabalho é: a escola, enquanto educadora e transformadora da sociedade, que trabalha com projetos de Educação Ambiental e contribui na mudança de hábitos com relação ao meio ambiente pode desenvolver, de fato, uma educação ambiental crítica?

Projetos como esse precisam primeiramente, atingir o centro principal do aprendizado, o aluno. Para tanto, os alunos precisam ter dimensão do problema do resíduo não separado ou não reciclados.

Justifica-se a escolha deste tema pela grande importância deste projeto para a escola e para todo o município contribuindo para uma Educação Ambiental efetiva auxiliando na preservação do meio ambiente, sobretudo a participação desses alunos na realização das ações.

O objetivo deste artigo é analisar a experiência educativa dos alunos do ensino fundamental II da EMEF "Sebastião Costa", mediante a participação no projeto educacional intitulado "Nova Mente".

O foco da pesquisa foram 68 alunos do Ensino Fundamental II da EMEF "Sebastião Costa" com idade entre 11 e 18 anos, letrados e alfabetizados, com variadas etnias, diversidades, culturas e poderes sócios econômicos, moradores da comunidade e moradores da zona rural.

Foram aplicados questionários semiabertos para análise e interpretação dos dados propiciando uma compreensão qualitativa do trabalho verificando e validando todas as informações que se pretende obter a respeito de seus conhecimentos sobre os tipos de resíduos e como separar os mesmos. 
O referencial teórico deste trabalho foi dividido em três seções. Na primeira relata um breve histórico do projeto desenvolvido pela instituição de ensino. A segunda narra o que diz nos Parâmetros Curriculares Nacionais sobre a Educação Ambiental. Na terceira, explicita o significado de Educação Ambiental Crítica na visão dos autores Layrargues e Lima.

\section{BREVE HISTÓRICO DO PROJETO INTITULADO “NOVA MENTE”}

Ciente de que a qualidade de vida está totalmente ligada à preservação do meio ambiente, a EMEF "Sebastião Costa", localizada no município de Muniz Freire, no estado Espírito Santo começou desenvolvendo ações de separação de resíduos dentro dos seus muros, fazendo um trabalho de conscientização ambiental com seus alunos e todo o corpo escolar, mas no fim, todos os resíduos eram misturados e levados para um lixão desestimulando alunos e funcionários a continuar com tais ações, situando- se, de acordo com Layrargues e Lima (2011), numa educação ambiental pragmática.

No ano de 2012, a escola iniciou o projeto "Ambiente limpo é aquele que não se suja", voltado para inúmeras ações com a finalidade de reduzir e dar destino adequado aos resíduos produzidos pela comunidade. Das ações propostas por esse projeto, foi concluída com êxito a retirada do lixão a céu aberto que existia às margens do rio Braço Norte Esquerdo que poluía o ambiente e comprometia a saúde dos 1600 moradores que eram obrigados a conviver com amontoados de resíduos a céu aberto poluindo o meio ambiente, abrigando animais nocivos à saúde, incluindo uma enorme concentração de cães servindo para transmitir doenças de pele, verminoses, entre outros. Destaca-se também, no desenvolvimento desse projeto, notáveis mudanças de hábitos e a preocupação constante dos moradores da comunidade com relação aos resíduos produzidos no que diz respeito à redução e ao seu destino.

Conhecendo a importância do tema desenvolvido pela escola juntamente com a comunidade, constatou-se a necessidade de redirecionar ações através de um novo projeto com o intuito de continuar envolvendo a comunidade de Itaici em atitudes voltadas, não só para a redução, mas principalmente para o reaproveitamento e 
destino dos resíduos, tendo em vista a melhoria da qualidade de vida e a preservação do meio ambiente.

O Projeto "Nova Mente", desenvolvido pela EMEF Sebastião Costa, tem por finalidade propor mudanças de hábitos no que diz respeito a redução e destino adequado dos resíduos, partindo da conscientização e sensibilização de alunos, professores e demais funcionários e expandindo-se para todos os grupos de convívio dessa comunidade, constituindo-se um projeto que abrange a educação formal e não formal.

Visto que a EMEF "Sebastião Costa" realiza ações na comunidade como a conscientização contínua dos moradores sobre a importância das mudanças de hábitos em relação à separação e reaproveitamento de resíduos através de palestras, distribuição de panfletos e esclarecimento de dúvidas nas casas entre outras ações.

A partir dessa iniciativa, verificam-se como resultados alcançados a retirada do lixão às margens do rio, a mudança de hábito de parte dos moradores em relação à separação dos resíduos recicláveis e não recicláveis e a diminuição dos resíduos produzidos. Os recipientes utilizados para colocar os resíduos não recicláveis que antes ficavam nas ruas, agora estão de posse dos moradores para conscientizar que de fato a responsabilidade é de cada um em dar destino adequado aos resíduos produzidos. Com o reaproveitamento de materiais são confeccionados brinquedos, jogos, objetos utilitários e ornamentais.

Foi realizado um documentário do funcionamento do projeto servindo de estímulo para outras regiões desenvolverem ações para melhoria do ambiente em que vivem. Atualmente a coleta dos resíduos recicláveis é feita pela escola, pelas igrejas locais e conduzidos para a Associação de Catadores na cidade de Muniz Freire contribuindo para o sustento de inúmeras famílias que dependem desse trabalho. Os resíduos não recicláveis são recolhidos pela Prefeitura Municipal de Muniz Freire e levados ao aterro sanitário.

Recentemente os alunos realizaram uma pesquisa de campo para averiguar o envolvimento da população local com as ações do projeto. Com essa pesquisa foram sanadas dúvidas e conhecimentos foram adquiridos para que este projeto continue fazendo a diferença na vida desta comunidade.

Porém, percebe-se que a maior parte das ações deste projeto tem sido voltadas para a comunidade. Dessa forma, através do estudo tenta-se verificar se a escola enquanto formadora de cidadãos autênticos e responsáveis com o meio em que 
vivem, com o desenvolvimento do mesmo dentro da educação formal e não formal tem conseguido mudar o comportamento ambiental de seus atores principais, os alunos.

\title{
3 A EDUCAÇÃO AMBIENTAL NOS PCN'S (PARÂMETROS CURRICULARES NACIONAIS)
}

Os Parâmetros Curriculares Nacionais são formados por um conjunto de princípios e objetivos criados para nortear e embasar a escola, professores em especial, a tratarem de assuntos pertinentes ao desenvolvimento social do aluno, os temas transversais.

A seção Meio Ambiente dos PCN's é dividida em duas partes.

\begin{abstract}
Nesta primeira parte, ainda, são apresentadas algumas reflexões sobre o processo educacional propriamente dito, com destaque para a explicitação de indicadores para a construção do ensinar e do aprender em Educação Ambiental. Na segunda parte, são apresentados os conteúdos, os critérios adotados para sua seleção neste documento, e a forma como eles devem ser tratados para atingir os objetivos desejados. (BRASIL, 1997, p.170)
\end{abstract}

Na seção "aprender e ensinar em Educação Ambiental”, nos PCN's assegura que

(...) a principal função do trabalho com o tema Meio Ambiente é contribuir para a formação de cidadãos conscientes, aptos para decidirem e atuarem na realidade socioambiental de um modo comprometido com a vida, com o bem-estar de cada um e da sociedade, local e global. (BRASIL, 1997, p.187)

Segundo este documento, este é um desafio para a educação, pois para alcançar esses objetivos a escola deve propor-se a "trabalhar com atitudes e a formação de valores, com o ensino e a aprendizagem de habilidades e procedimentos".

É importante, também, que o aluno estabeleça uma relação entre "o que aprende e a sua realidade cotidiana, da possibilidade de estabelecer ligações entre 0 que aprende e o que já conhece, e também da possibilidade de utilizar o conhecimento em outras situações" (BRASIL, 1997; p. 187)

Cabe ao educador "desenvolver essa postura crítica que é muito importante para os alunos, pois isso lhes permite reavaliar essas mesmas informações, percebendo os vários determinantes da leitura, os valores a elas associados e aqueles trazidos de casa." (BRASIL, 1997, p. 188)

Este documento também aborda o estudo meio ambiente nas "esferas global e local". 


\begin{abstract}
A perspectiva ambiental deve remeter os alunos à reflexão sobre os problemas que afetam a sua vida, a de sua comunidade, a de seu país e a do planeta. Para que essas informações os sensibilizem e provoquem o início de um processo de mudança de comportamento, é preciso que o aprendizado seja significativo, isto é, os alunos possam estabelecer ligações entre o que aprendem e a sua realidade cotidiana, e o que já conhecem. (BRASIL, 1997, p. 189-190)
\end{abstract}

Na seção "relação entre comunidade e escola" (...) "pode reavivar o debate entre alunos de várias idades e classes, entre toda a comunidade escolar, entre escola e bairro e ainda entre instâncias maiores da administração pública."

A partir de alguns critérios foram selecionados alguns conteúdos para que o professor trabalhe em sala de aula pensando no aspecto local, mas sem perder a visão global e ampliação de conhecimento sobre a realidade. (BRASIL, 1997, p. 203)

Os conteúdos foram divididos em três blocos:

- A natureza "cíclica" da Natureza

- Sociedade e meio ambiente

- Manejo e conservação ambiental

Dessa forma

(...) os blocos não são estanques, nem sequenciais, mas aglutinam conteúdos relativos aos diferentes aspectos que configuram a problemática ambiental. Eles possibilitam enxergar de maneira mais consistente esses determinantes dos vários ambientes, como eles se configuraram e como poderiam ser modificados. (BRASIL, 1997, p. 204)

Esses temas, juntamente com temas relacionados a outros assuntos são trabalhados transversalmente, paralelos aos conteúdos vigentes de sala de aula. Sendo assim, segundo Brasil (2000) a Educação Ambiental não é tratada como uma disciplina, mas trabalhada de forma transversal, paralela aos conteúdos da grade curricular. E esses temas são incorporados as aulas segundo a realidade e necessidade social.

\title{
4 A EDUCAÇÃO AMBIENTAL CRÍTICA
}

De acordo com Layrargues e Lima (2011, p.5) no final do século XX, com o desenvolvimento desenfreado surge a preocupação de uma eminente crise ambiental fazendo com o ser humano "humano adotasse uma visão de mundo e uma prática social capazes de minimizar os impactos ambientais então prevalecentes."

Segundo esses autores, nesse contexto, constataram que a Educação Ambiental compreendia um universo que girava em torno das relações entre o indivíduo, a sociedade, a natureza e a educação, exigindo aprofundamentos a cerca 
destas questões e crescente suporte teórico tornando a prática da Educação Ambiental mais complexa do que se poderia imaginar.

Quando mencionamos o termo Educação Ambiental imediatamente remetemos aos trabalhos desenvolvidos através de projetos nas instituições de ensino voltados, por exemplo, para o tema água com ações como o plantio de mudas nas nascentes, economia de água na escola, também é muito utilizado o tema lixo com ações como a separação de resíduos recicláveis, objetos confeccionados a partir deles, concursos de paródias, enfim, ações que por fim não mudam a realidade escolar e não levam em conta as questões sociais, políticas e econômicas da comunidade inserida, por isso essas ações não se consolidam como estilo de vida.

De acordo cm Layrargues e Lima (2011) é possível situar três macrotendências político-pedagógicas convivendo e disputando a hegemonia simbólica e objetiva do campo da 5 EA no Brasil: Conservacionista, Pragmática e Crítica.

De acordo os autores, a versão conservacionista

[...] apoia-se nos princípios da ecologia, na valorização da dimensão afetiva em relação à natureza e na mudança dos comportamentos individuais em relação ao ambiente baseada no pleito por uma mudança cultural que relativize 0 antropocentrismo como paradigma dominante. (LAYRARGUES e LIMA, 2011, p. 9)

Para eles, no início a Educação Ambiental tornou-se de caráter conservacionista objetivando a sensibilização do indivíduo com relação à natureza no âmbito de "conhecer para amar, amar para preservar" voltada para uma conscientização ecológica, face ao grande impacto e destruição ambiental causadas pelas ações desenfreadas do ser humano ao meio ambiente.

Segundo Gelsleithter; Slonski (2013) em seus estudos sobre as tendências de Layrarques e Lima (2011) "as vertentes, Conservacionista e Pragmática, representam duas tendências e dois momentos de uma mesma linhagem de pensamento que se foi ajustando às injunções econômicas e políticas do momento até ganhar essa face modernizada, neoliberal e pragmática que hoje a caracteriza."

Com o tempo, seguindo o raciocínio de Layrargues e Lima (2011), o desenvolvimento da Educação Ambiental foi se ramificando, levando em conta as questões sociais, formações profissionais, desenvolveu-se diversas correntes de pensamento sobre esse campo levando a construção de uma "relação entre educação e o meio ambiente". 
E, segundo os autores, à medida que essa diversidade interna se tornou visível, as análises buscaram problematizar esse fenômeno, fazendo da Educação Ambiental um objeto de estudo auto reflexivo que pensa sua própria prática e desenvolvimento.

\begin{abstract}
Essa auto reflexividade da Educação Ambiental acrescida da tomada de consciência sobre o seu papel no contexto da crise ambiental, pode ter promovido uma inflexão nos seus rumos: a vertente conservacionista deixou de ser a mais recorrente, ao menos entre os educadores ambientais próximos ao núcleo orientador do campo 2 , surgindo outros dois caminhos: a vertente crítica despontando como uma promissora alternativa capaz de realizar certo contraponto à vertente conservacionista; e a vertente pragmática, derivação ainda não tão nítida da vertente conservacionista, nutrindo-se inicialmente da problemática do lixo urbano-industrial como um dos temas cada vez mais utilizados nas práticas pedagógicas. (LAYRARGUES; LIMA, 2011, p. 7)
\end{abstract}

Continuando o pensamento de Layrargues e Lima (2011) a vertente crítica se constrói em oposição às vertentes conservadoras "procurando contextualizar e politizar o debate ambiental, articular as diversas dimensões da sustentabilidade e problematizar as contradições dos modelos de desenvolvimento e de sociedade que experimentamos local e globalmente."

Por essas razões, constatamos que a Educação Ambiental Crítica cresceu significativamente na última década, notadamente no âmbito acadêmico, e tem mostrado grande vitalidade para sair da condição de contra hegemonia e ocupar um lugar central no campo, atualmente ocupado pela macrotendência pragmática. (LAYRARGUES; LIMA, 2014, p. 34)

\title{
5 RESULTADOS E DISCUSSÃO
}

Em concordância com os autores Layrargues (2002), Layrargues e Lima (2011), Dias (1991) e Sato (2010) a Educação Ambiental na escola deve levar ao desenvolvimento crítico do aluno onde ele seja capaz de refletir e agir no meio em que vive, ou seja, dentro e fora da escola, exercendo sua cidadania.

Visto que a EMEF "Sebastião Costa" já trabalha o projeto de Educação Ambiental "Novamente", cujo objetivo é incentivar a separação e recolhimento dos resíduos da escola e da comunidade em que está inserida, foi realizada uma pesquisa com 68 alunos com idade entre 11 e 18 anos, letrados e alfabetizados, com variadas etnias, culturas e poderes sócios econômicos, moradores da comunidade e moradores da zona rural que são os principais protagonistas da coleta seletiva dos resíduos sólidos recicláveis, buscando fazer um diagnóstico sobre a atual situação do desenvolvimento do projeto. A partir desta pesquisa averiguamos a opinião, a satisfação e as mudanças significativas que o projeto trouxe para o comportamento dos alunos. 


\section{Gráfico 1- Porcentagem de alunos que consideram o projeto importante}

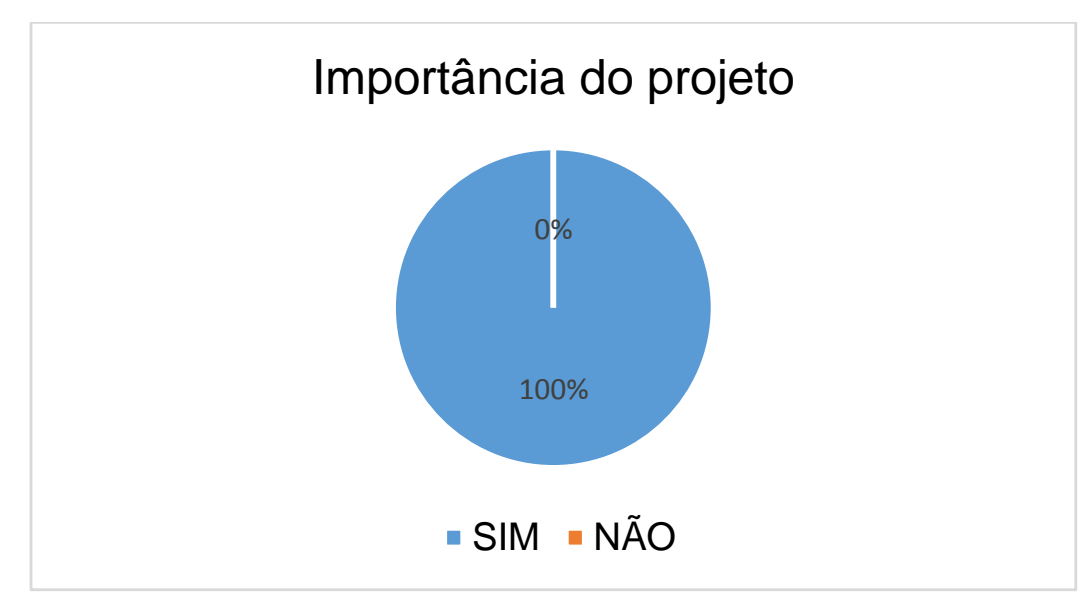

Com a pesquisa pode ser constatado que todos os alunos consideram este trabalho desenvolvido importante para a proteção do meio ambiente, para a escola e para comunidade contribuindo também, para ruas mais limpas.

Com relação à realização da separação dos resíduos na escola, a maior parte dos alunos relatou que realizam sim, mas quando perguntou sobre a separação em suas casas o número de alunos que realizam caiu significativamente.

\section{Gráfico 2- Destino dado aos rejeitos produzidos nas residências dos} alunos

\section{Destino dos rejeitos das casas}

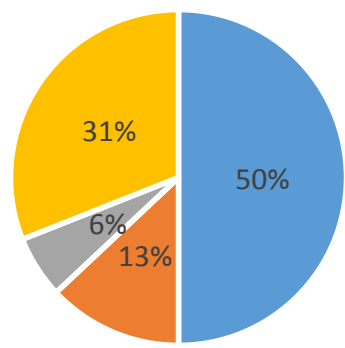

- Latão - Quintal - Rio -Queiimados

Quanto ao destino dos rejeitos, ou seja, do que não pode ser reciclado, cerca de $50 \%$ são depositados no latão, $13 \%$ jogam no quintal, $6 \%$ jogam no rio e $31 \%$ são queimados. Tendo em vista que, muitos são moradores da zona rural onde não há coleta de lixo e de resíduos. 
Gráfico 3- Porcentagem de resíduos encaminhados para reciclagem nas residências dos alunos

\section{Resíduos produzidos encaminhados para a reciclagem}

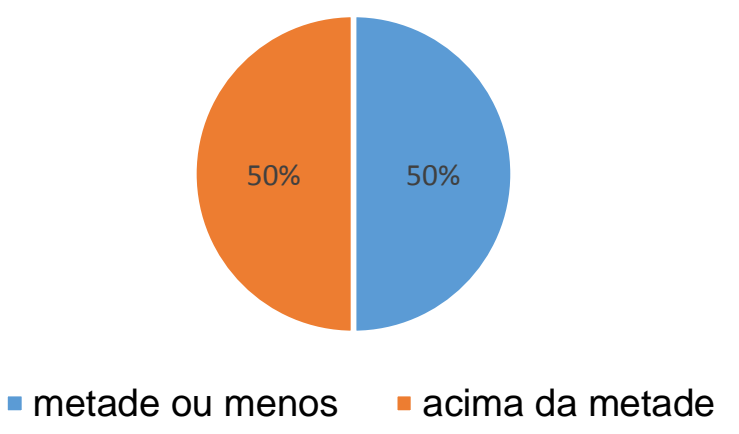

Metade dos alunos respondeu que somente $50 \%$ ou menos do lixo de sua residência é separado para coleta dos recicláveis e que poderia ter mais resíduos para a coleta seletiva que é jogado no o lixo comum, mas mesmo assim, a maioria, 94\%, relata que separar os resíduos da pouco ou nenhum trabalho.

Gráfico 4- Porcentagem de alunos sobre o destino dos resíduos recicláveis da escola

\section{Destino dos resíduos da escola}

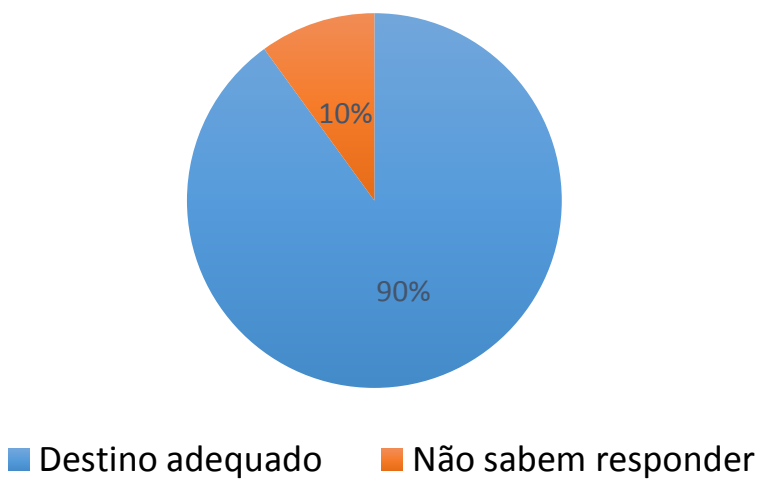

Cerca de $90 \%$, afirmam que os resíduos recicláveis da escola, bem como os resíduos orgânicos são encaminhados para o destino adequado.

Diante dos resultados alcançados percebe-se que na escola os alunos participam efetivamente do projeto, mas quando estão em suas residências há uma maior resistência em realizar a separação. Levando em conta que muitos são 
moradores da zona rural onde não há recolhimento do lixo e dos recicláveis, e também porque estão longe dos olhares do corpo docente.

Mas o interessante é que a maioria não considera difícil executar o projeto, que reconhece as melhorias trazidas por ele, tanto na escola como na comunidade e principalmente, que precisam melhorar suas posturas enquanto participantes efetivos da separação e coleta seletiva dos resíduos sólidos, significando que o projeto está no caminho certo, mas que ainda há muito que desenvolver na vida de seus protagonistas em busca de uma verdadeira Educação Ambiental Crítica.

\section{CONCLUSÃO}

O resultado desta pesquisa afirmou que a escola, enquanto educadora e transformadora da sociedade, que trabalha com projetos de Educação Ambiental pode contribuir na mudança de hábitos com relação ao meio ambiente e no comportamento de uma população desenvolvendo de fato uma Educação Ambiental Crítica nos espaços formais e não formais, mesmo a passos lentos.

O objetivo deste trabalho foi alcançado porque após a análise do resultado percebeu-se que está ocorrendo uma mudança significativa no comportamento ambiental dos alunos de uma forma gradual, mas que ainda tem muito a se fazer para uma efetiva mudança de mentalidade e atitudes dentro e principalmente, fora da escola.

Este trabalho torna-se relevante para a compreensão que 0 trabalho de Educação Ambiental na escola não é fácil, requer o esforço de todo o corpo docente para a conscientização dos alunos a respeito das situações de meio ambiente. Serão encontradas inúmeras barreiras e o processo de mudança de comportamento do ser humano é lento. Mas este trabalho mostra que é importante e válido a educação Ambiental na escola ao ver o progresso da mentalidade dos alunos, buscando uma verdadeira Educação Ambiental Crítica onde, de acordo com Layrargues e Lima (2011) a escola contribua para que o aluno seja participante ativo das questões sócio ambientais que o rodeiam, sendo capazes de atuar na realidade em que vivem estimulando-os a desenvolverem um pensamento crítico em relação a questões ambientais. 


\section{REFERÊNCIAS BIBLIOGRÁFICAS}

BRASIL. Secretaria de Educação Fundamental. Parâmetros curriculares nacionais: meio ambiente, saúde / Secretaria de Educação Fundamental. Brasília, 1997.

DIAS, G. F. Educação Ambiental: Princípios e Práticas. São Paulo, Gaia, 1991. In: GAYA, Marília Carla Mello; CHAVES, Rayssa Aguiar. O papel da escola na construção da educação ambiental: ações e reflexões. Revista SBEnBio- Associação Brasileira de Ensino de Biologia. N. 07. Out 2014. Disponível em: http://www.sbenbio.org.br/wordpress/wp-content/uploads/2014/11/R0691-1.pdf. Acesso em: 06 Dez. 2017

FERREIRA, José Edilson; PEREIRA, Saulo Gonçalves; BORGES, Daniela Cristina Silva. A Importância da Educação Ambiental no Ensino Fundamental. Revista Brasileira de Educação e Cultura. Número VII Jan-jun 2013 Páginas 104-119

GUIMARÃES, Mauro. A dimensão ambiental na educação. Campinas: Papirus, 1995.

LAKATOS, Eva Maria; MARCONI, Marina de Andrade. Fundamentos de metodologia científica. 5. ed. São Paulo: Atlas, 2003.

LAYRARGUES, P. P.; LIMA, G. F. da C. As macrotendências político-pedagógicas da educação ambiental brasileira. Ambiente e sociedade: São Paulo: vol.17 no.1 Jan./Mar. 2014

LAYRARGUES, P. P. Crise Ambiental e suas Implicações na Educação. In: QUINTAS J. S. (Org.): Pensando e praticando educação ambiental na gestão do meio ambiente. 2 ed. Brasília: Edições IBAMA, p. 159-196, 2002.

LAYRARGUES, P. P.; LIMA, G. F. da C. Mapeando as macro-tendências político pedagógicas daEducação ambiental contemporânea no Brasil. VI Encontro Pesquisa em Educação Ambiental: Ribeirão Preto, set. 2011.

SATO, Michele. Debatendo os desafios da Educação Ambiental. In: I Congresso de Educação Ambiental Pró Mar de Dentro. Rio Grande: Mestrado 3m Educação Ambiental, FURG e Pró Mar de Dentro, 2001.

SATO, Michele; TRAJBER, Rachel. Escolas sustentáveis: incubadoras de transformações nas comunidades. Revista Eletrônica de Mestrado em Educação Ambiental. PPGEA/FURG-RS v. especial, set 2010.

THIOLLENT, Michel. Metodologia da pesquisa-ação. São Paulo: Cortez, 1985. Pesquisa-ação nas organizações. São Paulo: Atlas, 1997. 